\title{
Effects of Heat Treatment on Lactone Content of Butter and Margarine
}

\author{
Kazuaki Yoshinaga ${ }^{1,2}$, Arisa Tago ${ }^{3}$, Aya Yoshinaga-Kiriake ${ }^{3}$, Toshiharu Nagai ${ }^{2}$, \\ Akihiko Yoshida ${ }^{2}$, and Naohiro Gotoh ${ }^{3 *}$ \\ ${ }^{1}$ Faculty of Food and Agricultural Sciences, Fukushima University, Kanayagawa, Fukushima 960-1248, JAPAN \\ ${ }^{2}$ Tsukishima Foods Industry Co. Ltd., 3-17-9 Higashi Kasai, Edogawa-ku, Tokyo 134-8520, JAPAN \\ ${ }^{3}$ Department of Food Science and Technology, Tokyo University of Marine Science and Technology, 4-5-7 Konan, Minato-ku, Tokyo 108-8477, \\ JAPAN
}

\begin{abstract}
The lactone content of butter, fermented butter, and margarine was compared using gas chromatography-mass spectrometry. The main lactones in butters and fermented butters consisted of $\delta$ decalactone, $\delta$-dodecalactone, $\delta$-tetradecalactone, $\delta$-hexadecalactone, and $\gamma$-dodecalactone. In contrast, the main lactones in margarines were $\delta$-decalactone and $\delta$-dodecalactone. The total lactone content in butters and fermented butters increased by approximately two-fold upon heat treatment, whereas, heat treatment did not affect the lactone content in margarine. The changes in lactone content caused by heat treatment were greater in fermented butters than in butters. These findings suggested that the fermentation process could increase lactone or lactone precursor content in butter.
\end{abstract}

Key words: gas chromatography, lactones, milk fat, quantification

\section{Introduction}

Butter flavor can be attributed to a mixture of many volatile compounds. More than 230 volatile compounds have been identified as natural constituents of milk fat ${ }^{1)}$. Among them, lactones are important compounds that impart flavor to butter and other dairy products. Therefore, these are used as flavor additives for the production of margarines to enhance their butter flavor. To date, many researchers have studied the lactone composition of milk fat. For instance, $\delta$-decalactone as a coconut-like flavor of milk fat was identified by Keeny et $a l .{ }^{2}$, and $\delta$-decalactone and $\delta$-dodecalactone were detected from the steam distillate of butter by Tharp et $a l .{ }^{3)}$. Boldingh et al. detected $\delta$-octalactone, $\delta$-decalactone, $\delta$-dodecalactone, $\delta$-tetradecalactone, and smaller amounts of $\gamma$-lactones in milk fat as desirable contributors to the flavor of butter ${ }^{4)}$. Siek et al. compared the aroma thresholds of the individual lactones, and reported the thresholds for $\delta$-octalactone, $\delta$-decalactone, $\delta$-dodecalactone, and $\delta$-tetradecalactone as $3.0,1.4,95.0$, and $500 \mathrm{ppm}$ in oil, respectively; the thresholds in water were 5 to 950 times lower than those in oil ${ }^{5}$. Although short chain lactones indicate lower thresholds than long chain lactones based on the differences in their individual volatilities, it is known that semi-volatile lactones, such as $\delta$-tetradecalactone, contribute to the typical creamy flavor of butter ${ }^{6}$. These points indicate that it is important to analyze various lactones to estimate the flavor of butter and margarine. Interestingly, the characteristics of butter differ from those of margarine; for example, the amount of lactones increases when butter is heated in the presence of water ${ }^{4,7,8)}$. The released lactone content after heat treatment is defined as the lactone potential. Many researchers have investigated the origin of lactone in milk, and suggested that the precursors of $\gamma$ - and $\delta$-lactones are 4- and 5-hydroxy fatty acids, respectively. Furthermore, hydroxy fatty acids are likely esterified in triacylglycerol $(\mathrm{TAG})^{4,8-11)}$. Recently, we developed an analytical method for the quantification of hydroxy TAG isomers comprising two palmitic acids and one 4- or 5-hydroxy fatty acid in milk fat using LC-ESI-MS/MS, and confirmed that all isomers were easily converted into their respective lactones following heat treatment at $160^{\circ} \mathrm{C}$ for $2 \mathrm{~h}$ in the presence of water ${ }^{12)}$. It is considered to include hydrolysis of the hydroxy fatty acid from TAG during lactonization of

\footnotetext{
*Correspondence to: Naohiro Gotoh, Department of Food Science and Technology, Tokyo University of Marine Science and Technology, 4-5-7 Konan, Minato-ku, Tokyo 108-8477, JAPAN

E-mail: ngotoh@kaiyodai.ac.jp

Accepted October 25, 2019 (received for review September 17, 2019)
}

Journal of Oleo Science ISSN 1345-8957 print / ISSN 1347-3352 online

http://www.jstage.jst.go.jp/browse/jos/ http://mc.manusriptcentral.com/jjocs 
hydroxy TAG by heat treatment; the esterified hydroxy fatty acids are hydrolyzed from TAG to free fatty acids by heating, and then the free hydroxy fatty acids are immediately lactonized. However, Alewijn et al. observed the formation of lactones during the ripening of Gouda cheese ${ }^{13)}$. They also proposed that the direct lactonization of hydroxy fatty acids esterified in TAG without hydrolysis, and suggested that water plays a catalytic role in the proposed reaction $^{14)}$.

The lactone composition of milk fat is affected by environmental factors such as the season, feeding regime, and stage of lactation ${ }^{15-18)}$. For instance, milk from cows fed hay exhibited higher lactone content than that of milk from cows on pasture, and more significant effects of forage types were observed in the content of $\gamma$-lactones than in $\delta$-lactones in milk ${ }^{18)}$. The lactone content of milk fat is also influenced by manufacturing conditions such as the fermentation process of butter. For example, sweet butter was characterized by the presence of $\delta$-hexalactone, $\delta$-octalactone, and $\gamma$-dodecalactone. In particular, $\delta$-hexalactone and $\gamma$-dodecalactone had creamy and peachlike odors, respectively ${ }^{19)}$. In contrast, fermented butter had higher amounts of $\delta$-decalactone, diacetyl, butanoic, and hexanoic acids than sweet butter. This might be attributed to the presence of lactic acid bacteria, which are added to the cream during fermented butter production ${ }^{20)}$. These are important issues for food manufacturing. Therefore, more information regarding lactone composition in dairy products and margarine is required to improve the quality of food products. The present study aimed to investigate free lactone composition of butter, fermented butter, and margarine in Japan. Lactones were analyzed by our developed method using gas chromatography-mass spectrometry (GC-MS) after solvent extraction ${ }^{21)}$. In addition, the lactone potentials of butter, fermented butter, and margarine were estimated by analyzing the samples after heat treatment.

\section{Experimental}

\subsection{Chemicals and Materials}

Sweet butter, fermented butter, and margarine were purchased from local supermarkets in Tokyo to be used as samples. The manufacture dates of butter and fermented butter samples were within one month prior to the date of purchase. Margarines to which butter was not added were selected in this study. Lactone samples used in this study - $\delta$-hexalactone, $\delta$-octalactone, $\delta$-decalactone, $\delta$-undecalactone, $\delta$-dodecalactone, $\delta$-tetradecalactone, $\gamma$-hexalactone, $\gamma$-heptalactone, $\gamma$-octalactone, $\gamma$-nonalactone, $\gamma$-decalactone, $\gamma$-undecalactone, and $\gamma$-dodecalactone - were purchased from the Tokyo Chemical Industry Co., Ltd. (Tokyo, Japan) (Fig. 1). $\delta$-Hexadecalactone was synthesized as described in our previous study ${ }^{211}$.

\subsection{Preparation of butter, fermented butter, and margarine}

Fat and oil were extracted from the purchased butter, fermented butter, and margarine through the Folch procedure $^{22)}$. These were diluted nine-fold (by volume) with saturated saline solution. The diluted solution was added to double its volume of a mixture of chloroform and methanol $(2 / 1, \mathrm{v} / \mathrm{v})$ in a test tube equipped with a screw cap, and the mixture was mixed vigorously with a vortex mixer and centrifuged at $1,500 \times g$ for $10 \mathrm{~min}$. The bottom layer was removed and dried using a nitrogen stream at room temperature, and the fat and oil were finally obtained.

To compare the lactone potentials of butter, fermented butter, and margarine, the fat and oil were heated at $160^{\circ} \mathrm{C}$ for $2 \mathrm{~h}$ in the presence of $1 \%(\mathrm{w} / \mathrm{w})$ water, and then dried over anhydrous sodium sulfate; these samples were used as the heat-treated samples.

\subsection{Analysis of lactone by GC-MS}

Lactone content of the heat-treated samples was determined based on a procedure developed by Obi et al. ${ }^{21)}$. A $0.5 \mathrm{~g}$ sample was transferred to a screw-capped tube and mixed with $1 \mathrm{~mL}$ of methanol and $0.5 \mathrm{~mL}$ of a $30 \mu \mathrm{g} / \mathrm{mL}$ solution of $\delta$-undecalactone in methanol as an internal standard. After centrifugation at $4,000 \times g$ and $4^{\circ} \mathrm{C}$ for $4 \mathrm{~min}$, the top layer was removed and added to another tube. To eliminate TAG, the samples were frozen $\left(-30^{\circ} \mathrm{C}\right)$ for $10 \mathrm{~min}$ to recrystallize TAG and further centrifuged at $6,000 \times g$ and $4^{\circ} \mathrm{C}$ for $30 \mathrm{~s}$. The methanol layer was then removed and placed in a vial.

The analysis was performed using a GC-MS system (GC: TRACE 1310, MS: ISQ7000, Thermo Fisher Scientific, Waltham, USA) equipped with a capillary column (IntertCap Pure-WAX, $30 \mathrm{~m} \times 0.25 \mathrm{~mm}$ i.d., $0.25 \mu \mathrm{m}$ thickness, GL Sciences Ltd., Tokyo, Japan). The column temperature was programed to remain at $60^{\circ} \mathrm{C}$ for $6 \mathrm{~min}$, then raised to $250^{\circ} \mathrm{C}$ at $5^{\circ} \mathrm{C} / \mathrm{min}$ and held for $20 \mathrm{~min}$. The injector temperature was set at $250^{\circ} \mathrm{C}$. The flow rate of the carrier gas (helium) was $1.0 \mathrm{~mL} / \mathrm{min}$. The split ratio was $50: 1(\mathrm{v} / \mathrm{v})$, and the injection volume was $1.0 \mu \mathrm{L}$. The MS was operated in electron impact ionization mode at $70 \mathrm{eV}$. The analysis was performed in the selected ion monitoring (SIM) mode. The target compounds were detected at $\mathrm{m} / \mathrm{z} 85$ ( $\gamma$-lactones), $\mathrm{m} /$ $z 42$ ( $\delta$-hexalactone), and $m / z 99$ ( $\delta$-octalactone, $\delta$-decalactone, $\delta$-undecalactone, $\delta$-dodecalactone, and $\delta$-tetradecalactone). The lactone content ( $\mu \mathrm{g} / \mathrm{g}$ oil) was calculated using the calibration curves and peak areas in the chromatogram. All analyses were performed thrice and each result represents the mean value. 
<smiles>CC1CCCC(=O)O1</smiles><smiles>CCCC1CCCC(=O)O1</smiles><smiles>CCCCCC1CCCC(=O)O1</smiles>

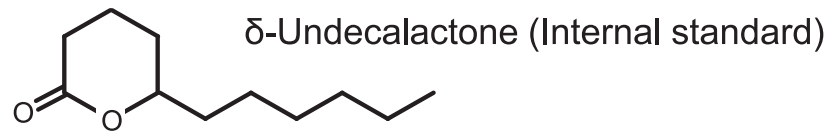<smiles>CCCCCCCC1CCCC(=O)O1</smiles><smiles>CCCCCCCCCC1CCCC(=O)O1</smiles><smiles>CCCCCCCCCCCC1CCCC(=O)O1</smiles>

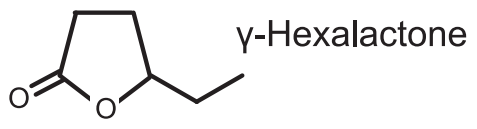<smiles>CCCC1CCC(=O)O1</smiles><smiles>CCCCC1CCC(=O)O1</smiles><smiles>CCCCCC1CCC(=O)O1</smiles><smiles>CCCCCCC1CCC(=O)O1</smiles><smiles>CCCCCCCC1CCC(=O)O1</smiles><smiles>CCCCCCCCC1CCC(=O)O1</smiles>

Fig. 1 Structures of lactones used in this study.

\section{Results and Discussion}

Table 1 shows the lactone content of butter, fermented butter, and margarine samples. The total lactone content of butter, fermented butter, and margarine were in the range of 57.9-67.9 $\mu \mathrm{g} / \mathrm{g}$ oil, $61.9-83.9 \mu \mathrm{g} / \mathrm{g}$ oil, and $25.1-$ $111.2 \mu \mathrm{g} / \mathrm{g}$ oil, respectively. Compared to butter, total lactone content of fermented butter tended to be higher. In butter and fermented butter, the main lactones were $\delta$-decalactone, $\delta$-dodecalactone, $\delta$-tetradecalactone, $\delta$-hexadecalactone, and $\gamma$-dodecalactone. The amount of lactone obtained was consistent with that reported in previous studies ${ }^{23,24)}$. The content of $\delta$-decalactone, $\delta$-dodecalactone, $\delta$-tetradecalactone, and $\delta$-hexadecalactone in fermented butter tended to be higher than that in butter.
These results suggested that the fermentation process can increase the free $\delta$-lactone content of milk fat by enhancing the formation of lactone from lactone precursors or production of lactone precursors. In contrast, the main lactones in margarines were $\delta$-decalactone and $\delta$-dodecalactone. The lactone content of margarines differed widely according to their type. Since margarines used in this study were butter-free products, these lactones could be derived from flavor additives. $\delta$-Decalactone and $\delta$-dodecalactone, which exhibit creamy and buttery flavors, respectively, could be used in margarine production to imitate butter flavor.

Table 2 shows lactone contents in heat-treated butter, fermented butter, and margarine samples. Previous studies 
K. Yoshinaga, A. Tago, A. K. Yoshinaga et al.

Table 1 Lactone content ( $\mu \mathrm{g} / \mathrm{g}$ oil) in butter, fermented butter, and margarine.

\begin{tabular}{|c|c|c|c|c|c|c|c|c|c|}
\hline \multirow{2}{*}{ Lactones } & \multicolumn{3}{|c|}{ Butter } & \multicolumn{3}{|c|}{ Fermented butter } & \multicolumn{3}{|c|}{ Margarine } \\
\hline & A & $\mathrm{B}$ & $\mathrm{C}$ & A & B & $\mathrm{C}$ & A & B & $\mathrm{C}$ \\
\hline$\delta$-hexalactone & 2.2 & 2.2 & 2.1 & 2.1 & 1.9 & 2.1 & 1.9 & 1.6 & 1.9 \\
\hline$\delta$-octalactone & 2.3 & 2.3 & 2.1 & 2.2 & 2.4 & 2.4 & 2.9 & 1.6 & 1.9 \\
\hline$\delta$-decalactone & 9.4 & 8.8 & 8.9 & 9.2 & 10.8 & 11.0 & 40.6 & 24.2 & 10.7 \\
\hline$\delta$-dodecalactone & 17.4 & 16.1 & 18.0 & 16.8 & 21.1 & 21.8 & 54.3 & 10.2 & 9.8 \\
\hline$\delta$-tetradecalactone & 17.7 & 16.4 & 19.4 & 16.7 & 22.7 & 23.4 & n.d. & 0.5 & n.d. \\
\hline$\delta$-hexadecalactone & 10.2 & 8.2 & 11.5 & 9.6 & 14.8 & 15.0 & n.d. & n.d. & n.d. \\
\hline$\gamma$-hexalactone & n.d. & n.d. & n.d. & n.d. & n.d. & n.d. & 2.5 & n.d. & n.d. \\
\hline$\gamma$-heptalactone & n.d. & n.d. & n.d. & 0.8 & n.d. & 0.8 & 0.8 & 0.8 & 0.8 \\
\hline$\gamma$-octalactone & n.d. & n.d. & n.d. & n.d. & n.d. & n.d. & n.d. & n.d. & n.d. \\
\hline$\gamma$-nonalactone & n.d. & n.d. & 0.8 & n.d. & 0.8 & n.d. & 1.5 & 1.2 & n.d. \\
\hline$\gamma$-decalactone & 0.9 & n.d. & 0.8 & 0.8 & n.d. & 0.9 & 1.2 & 1.8 & n.d. \\
\hline$\gamma$-undecalactone & n.d. & n.d. & n.d. & n.d. & n.d. & n.d. & 3.3 & n.d. & n.d. \\
\hline$\gamma$-dodecalactone & 3.0 & 3.9 & 4.3 & 3.6 & 3.6 & 6.6 & 2.2 & 0.8 & n.d. \\
\hline Total & 63.0 & 57.9 & 67.9 & 61.9 & 78.1 & 83.9 & 111.2 & 42.7 & 25.1 \\
\hline
\end{tabular}

Each result represents mean value $(\mathrm{n}=3)$.

n.d.: not detected (less than $0.5 \mu \mathrm{g} / \mathrm{g}$ oil).

Table 2 Lactone content ( $\mu \mathrm{g} / \mathrm{g}$ oil) in heat-treated butter, fermented butter, and margarine.

\begin{tabular}{lrrrrrrrrr}
\hline \multirow{2}{*}{ Lactones } & \multicolumn{3}{c}{ Butter } & \multicolumn{4}{c}{ Fermented butter } & \multicolumn{3}{c}{ Margarine } \\
\cline { 2 - 11 } & \multicolumn{1}{c}{ A } & \multicolumn{1}{c}{ B } & \multicolumn{1}{c}{ C } & \multicolumn{1}{c}{ A } & B & C & A & B & C \\
\hline$\delta$-hexalactone & 3.6 & 3.3 & 3.4 & 3.9 & 3.7 & 3.5 & 1.9 & 1.6 & 1.9 \\
$\delta$-octalactone & 2.9 & 2.7 & 2.6 & 2.9 & 3.1 & 3.1 & 2.9 & 1.6 & 1.9 \\
$\delta$-decalactone & 12.1 & 11.9 & 11.7 & 13.5 & 14.6 & 15.6 & 41.3 & 25.4 & 11.1 \\
$\delta$-dodecalactone & 24.4 & 24.8 & 25.0 & 27.4 & 30.6 & 31.4 & 56.6 & 10.4 & 9.9 \\
$\delta$-tetradecalactone & 28.1 & 28.4 & 33.0 & 30.2 & 35.5 & 37.0 & n.d. & 0.5 & n.d. \\
$\delta$-hexadecalactone & 26.4 & 31.8 & 31.9 & 30.4 & 37.7 & 38.2 & n.d. & n.d. & n.d. \\
$\gamma$-hexalactone & 5.4 & 4.1 & 4.7 & 4.8 & 4.8 & 4.5 & 2.5 & n.d. & n.d. \\
$\gamma$-heptalactone & 3.8 & 3.0 & 3.2 & 3.3 & 3.7 & 3.5 & 0.8 & 0.8 & 0.8 \\
$\gamma$-octalactone & 4.3 & 3.6 & 3.8 & 3.7 & 4.3 & 4.3 & 0.7 & n.d. & 0.7 \\
$\gamma$-nonalactone & 6.1 & 5.6 & 5.6 & 5.9 & 6.3 & 6.6 & 1.4 & 1.2 & 0.8 \\
$\gamma$-decalactone & 3.7 & 3.2 & 3.4 & 3.2 & 3.8 & 4.1 & 1.2 & 1.8 & n.d. \\
$\gamma$-undecalactone & 2.5 & 2.6 & 2.6 & 2.6 & 3.0 & 3.1 & 3.3 & 0.9 & n.d. \\
$\gamma$-dodecalactone & 6.5 & 9.2 & 8.4 & 9.2 & 7.6 & 12.1 & 2.2 & 0.8 & n.d. \\
\hline Total & 129.7 & 134.3 & 139.3 & 141.0 & 158.6 & 167.1 & 114.6 & 44.9 & 27.1
\end{tabular}

Each result represents mean value $(n=3)$.

n.d.: not detected (less than $0.5 \mu \mathrm{g} / \mathrm{g}$ oil).

showed that the heating process of butter converted 4- and 5-hydroxy fatty acid esters bound with TAG into $\gamma$-lactones and $\delta$-lactones, respectively. Moreover, the maximum amounts of the major lactones were attained after heating at $160^{\circ} \mathrm{C}$ for approximately an hour. The lactone content of butter after heat processing was higher than the original lactone content ${ }^{13,14)}$. In this study, we quantified lactone content in samples heated at $160^{\circ} \mathrm{C}$ for $2 \mathrm{~h}$ (Table 2). The total lactone content in butter, fermented butter, and margarine were in the range of $129.7-139.3 \mu \mathrm{g} / \mathrm{g}$ oil, 141.0 $167.1 \mu \mathrm{g} / \mathrm{g}$ oil, and $27.1-114.6 \mu \mathrm{g} / \mathrm{g}$ oil, respectively. The total lactone content of butters and fermented butters in- 
Effect of Heat Treatment on Lactones in Butter and Margarine

Table 3 Increasing rate of lactones (\%) by heat-treatment.

\begin{tabular}{lcccccc}
\hline \multirow{2}{*}{ Lactones } & \multicolumn{3}{c}{ Butter } & \multicolumn{4}{c}{ Fermented butter } \\
\cline { 2 - 7 } & A & B & C & A & B & C \\
\hline$\delta$-hexalactone & 66 & 51 & 67 & 80 & 91 & 69 \\
$\delta$-octalactone & 29 & 20 & 24 & 29 & 30 & 30 \\
$\delta$-decalactone & 28 & 34 & 31 & 46 & 35 & 42 \\
$\delta$-dodecalactone & 40 & 55 & 39 & 63 & 45 & 44 \\
$\delta$-tetradecalactone & 59 & 74 & 70 & 81 & 56 & 58 \\
$\delta$-hexadecalactone & 160 & 288 & 177 & 216 & 155 & 155 \\
$\gamma$-hexalactone & - & - & - & - & - & - \\
$\gamma$-heptalactone & - & - & - & 318 & - & 343 \\
$\gamma$-octalactone & - & - & - & - & - & - \\
$\gamma$-nonalactone & - & - & 568 & - & 654 & - \\
$\gamma$-decalactone & 328 & - & 313 & 282 & - & 377 \\
$\gamma$-undecalactone & - & - & - & - & - & - \\
$\gamma$-dodecalactone & 117 & 134 & 95 & 158 & 110 & 83 \\
\hline
\end{tabular}

Each result represents mean value $(n=3)$.

creased by approximately two-fold following heat treatment. In non-heat-treated butters (Table 1), $\gamma$-lactones, except for $\gamma$-dodecalactone, were scarcely detected (less than $0.5 \mu \mathrm{g} / \mathrm{g}$ oil). However, the lactone distribution of heat-treated butter showed that the $\gamma$-lactone content was evidently increased by heat treatment (Table 2). Increasing rates of lactones (\%) by heat treatment of butter and fermented butter are shown in Table 3. Comparison of the increasing rates of $\delta$-lactones indicated that the rates of $\delta$-hexadecalactone were higher than those of other $\delta$-lactones. These results suggested that considerable amounts of 4- and 5-hydroxy fatty acids, as precursors of $\delta$-hexadecalactone and $\gamma$-lactones, exist in butter and fermented butter, and that the stabilities of these hydroxy fatty acids are higher than those of other hydroxy fatty acids. We previously compared the heat stabilities of hydroxy TAG isomers as precursors of $\delta$-decalactone, $\delta$-dodecalactone, and $\delta$-tetradecalactone, and reported that the heat stabilities were lower for lactones with shorter carbon chains ${ }^{12)}$. Therefore, the heat stabilities of $\delta$-lactone precursors having less than 16 carbon chains could be lower than that of $\delta$-hexadecalactone, and then some shorter chain lactone precursors could be transformed into corresponding lactones at room temperature. Interestingly, the increasing rate of $\delta$-hexalactone was higher than that of $\delta$-lactone with $8-12$ carbon chains. Boldingh et al. compared the heat stabilities of TAG and monoacylglycerol(MAG) comprising 5-hydroxy fatty acid, and observed that hydroxy TAG was more heat stable than hydroxy MAG. It is suggested that the chemical structure of lactone precursors could influence the amount of lactone released by heat treatment ${ }^{4)}$. Therefore, further studies are needed to investigate the chemical structure of lactone precursors and their heat stabilities. In contrast, heat treatment did not affect lactone content in margarine. In general, butter flavor additives, widely used for food production, are derived from natural butter, synthetic lactones, or both. There is a high possibility that flavor additives derived from natural butter will contain lactone precursors. If margarine, which uses natural flavor additives, was heated, the amounts of lactone would be increased. Therefore, it is suggested that margarines analyzed in this study were manufactured using synthetic flavor.

Comparison of the lactone potentials between butter and fermented butter (Table 2) showed that the total lactone content of fermented butter tended to be higher than that of butter. This suggested that fermentation of milk could increase lactone precursors. A previous study reported that lactic acid bacteria can increase the amounts of $\delta$-decalactone ${ }^{20)}$. In the present study, the amount of $\delta$-decalactone, $\delta$-dodecalactone, $\delta$-tetradecalactone, and $\delta$-hexadecalactone in fermented butters tended to be higher than that in butters. These results suggested that the fermentation process of milk can increase $\delta$-lactones. However, the lactone composition of butter and fermented butter differed widely according to milk origin and the fermentation process. Therefore, it is difficult to elucidate the detailed mechanism of lactone increase from the results of the current study. In the future, we intend to clarify the effect of the fermentation process on lactone potential in butter by processing milk from the same source. It is speculated that if the GC-MS method employed in this study is made widely available for the quantification of lactones in butter and margarine, it would play an important role in 
K. Yoshinaga, A. Tago, A. K. Yoshinaga et al.

estimating the quality of food products.

\section{Conclusion}

Butter is a valuable fat in food manufacturing because of its attractive flavor. Heating process is always included during food manufacturing. Therefore, butter is a superior fat among the edible fats and oils because the lactone content of butter is increased by heat treatment. In the present study, we quantified lactones in butter, fermented butter, and margarine, and observed that the lactone content of butter and fermented butter was increased upon heat treatment. We also observed that the fermentation process can increase lactones or hydroxy fatty acids as lactone precursors in butter. In contrast, the lactone composition of margarines was not increased by heat treatment. The lactone distribution of margarines differed from butter and fermented butter. These characteristics revealed there are some good qualities of butter that margarine should imitate and/or improve to exceed the quality of butter. Consequently, lactone analysis using heat treatment can estimate the flavor potential of butter, fermented butter, and margarine.

\section{Conflict of Interest}

The authors declare no conflicts of interest.

\section{References}

1) Mallia, S.; Escher, F.; Schlichtherle-Cerny, H. Aromaactive compounds of butter: a review. Eur. Food Res. Technol. 226, 315-325 (2008).

2) Keeny, P.G.; Patton, S. The coconut like flavor defect of milk fat. I. Isolation of the flavor compound from butter oil and its identification as $\delta$-decalactone. $J$. Dairy Sci. 39, 1104-1113(1956).

3) Tharp, B.W.; Patton, S. Coconut-like flavor defect of milk fat. IV. Demonstration of $\delta$-dodecalactone in the steam distillate from milk fat. J. Dairy Sci. 43, 475479 (1960).

4) Boldingh, J.; Taylor, R. Trace constituents of butterfat. Nature 194, 909-913(1962).

5) Siek, T.J.; Albin, I.A.; Sather, L.A.; Lindsay, R.C. Comparison of flavor thresholds of aliphatic lactones with those of fatty acids, esters, aldehydes, alcohols, and ketones. J. Dairy Sci. 54, 1-4(1971).

6) Schlutt, B.; Moran, N.; Schieberle, P.; Hofmann, T. Sensory-directed identification of creaminess-enhancing volatiles and semivolatiles in full-fat cream. $J$. Agric. Food Chem. 55, 9634-9645 (2007).
7) Mattick, L.R.; Patton, S.; Keeney, P.G. The coconutlike flavor defect from milk fat, III: Observations on the origin of $\delta$-decalactone in fat-containing dairy products. J. Dairy Sci. 42, 791-798(1959).

8) Parliment, T.H.; Nawer, W.W.; Fagerson, I.S. Origin of delta-lactones in heated milk fat. J. Dairy Sci. 49, 1109-1112 (1966).

9) Jurriens, G.; Oele, J.M. Occurrence of esterified hydroxy fatty acids as precursors of lactones in butter. Nature 207, 864-865 (1965).

10） Kinsella, J.E.; Patton, S.; Dimick, P.S. Chromatographic separation of lactone precursors and tentative identification of the $\gamma$-lactones of 4-hydroxy octanoic and 4-hydroxy nonanoic acids in butterfat. J. Am. Oil Chem. Soc. 44, 202-205 (1967).

11) Wyatt, C.J.; Pereira, R.L.; Day, E.A. The lactone precursor in fresh milk fat: Identification of the hydroxy acids. Lipids 2, 208-211 (1967).

12) Yoshinaga, K.; Obi, J.; Tago, A.; Kato, Y.; Nagai, T.; Yoshida, A.; Gotoh, N. Analysis of hydroxy triacylglycerol as a lactone precursor in milk fat using liquid chromatography electrospray ionization tandem mass spectrometry. Food Chem. 274, 298-304(2019).

13) Alewijn, M.; Sliwinski, E.L.; Wouters, J.T.M. A fast and simple method for quantitative determination of fatderived medium and low-volatile compounds in cheese. Int. Dairy J. 13, 733-741 (2003).

14） Alewijn, M.; Sliwinski, E.L.; Wouters, J.T.M. Production of fat-derived (flavour) compounds during the ripening of Gouda cheese. Int. Dairy J. 15, 733-740 (2005).

15) Dimick, P.S.; Harner, J.L. Effect of environmental factors on lactone potential in bovine milk fat. J. Dairy Sci. 51, 22-27 (1968).

16) Urbach, G.; Stark, W. The effect of diet on the gammaand delta-lactone and methyl ketone potentials of bovine butterfat. J. Dairy Res. 45, 223-229 (1978).

17) Urbach, G. Effect of feed on flavor in dairy foods. $J$. Dairy Sci. 73, 3639-3650 (1990).

18) Villeneuve, M.P.; Lebeuf, Y.; Gervais, R.; Tremblay, G.F.; Vuillemard, J.C.; Fortin, J.; Chouinard, P.Y. Milk volatile organic compounds and fatty acid profile in cows fed timothy as hay, pasture, or silage. J. Dairy Sci. 96, 7181-7194(2013).

19) Peterson, D.G.; Reineccius, G.A. Characterization of the volatile compounds that constitute fresh sweet cream butter aroma. Flavor Fragr. J. 18, 215-220 (2003).

20) Schieberle, P.; Gassenmeier, K.; Guth, H.; Sen, A.; Grosch, W. Character impact odour compounds of different kinds of butter. Lebensm. Wiss. Technol. 26, 347356 (1993).

21) Obi, J.; Yoshinaga, K.; Tago, A.; Nagai, T.; Yoshida, A.; Beppu, F.; Gotoh, N. Simple quantification of lactones in milk fat by solvent extraction using gas chromatog- 
raphy-mass spectrometry. J. Oleo Sci. 67, 941-948 (2018).

22) Folch, J.; Lees, M.; Sloane-Stanley, G.H. A simple method for the isolation and purification of total lipids from animal tissues. J. Biol. Chem. 226, 497-509 (1957).

23) Kinsella, J.E.; Patton, S.; Dimick, P.S. The flavor po- tential of milk fat. A review of its chemical nature and biochemical origin. J. Am. Oil Chem. Soc. 44, 449454(1967).

24) Dimick, P.S.; Walker, N.J.; Patton, S. Occurrence and biochemical origin of aliphatic lactones in milk fat-A review. J. Agr. Food Chem. Soc. 17, 649-655(1969). 